THIS IS A PRE-PRINT. THE PAPER IS CURRENTLY UNDERGOING PEER-REVIEW AND IS SUBJECT TO CHANGE.

Partisanship and Political Work:

Differential Associations of Partisan Identification and Partisan Narcissism with Politicians' Skills and Performance

Bjarki Gronfeldt

University of Kent

Aleksandra Cichocka

University of Kent and Nicolaus Copernicus University

Aleksandra Cislak

SWPS University of Social Sciences and Humanities

Madeleine Wyatt

University of Kent

Author Note

Bjarki Gronfeldt, University of Kent. Aleksandra Cichocka, University of Kent and Nicolaus Copernicus University. Aleksandra Cislak, SWPS University of Social Sciences and Humanities. Madeleine Wyatt, University of Kent.

We have no known conflict of interest to disclose.

Correspondence concerning this article should be addressed to Bjarki Gronfeldt, School of Psychology, Keynes College, University of Kent, Canterbury, Kent CT2 7NP, UK. Email: b.gronfeldt-gunnarsson@kent.ac.uk 


\begin{abstract}
In this research, we investigate the role of partisan identity in predicting political skills, performance, and intragroup behavioural intentions among political elites. We differentiate the strength of partisan identification from partisan narcissism - a belief in the greatness of one's political party that is not appreciated by others. We recruited active political party members who had run for office in recent elections in Iceland $(N=214)$ to participate in an online survey. We found that partisan identification was related to higher levels of political skills and political performance, including higher analytical skills and ability to represent others. Partisan identification also predicted higher party loyalty and more time spent volunteering in party activities. Meanwhile, partisan narcissism was only related to politicking - the inclination to engage in secrecy, deception, and political blood-sport. Cumulatively, these results suggest that partisan identification is associated with meticulousness and representation of others in politicians' work. Conversely, partisan narcissism seems to contribute to being cunning in the political arena.
\end{abstract}

Keywords: partisanship, political workers, collective narcissism, in-group identification, political elites 
Partisanship and Political Work:

Differential Associations of Partisan Identification and Partisan Narcissism with Politicians' Skills and Performance

Partisanship and party identification seem to have a negative reputation, both in public discourse and in academic research (Bump, 2019; Drutman, 2017; Gaskell, 2020; Lelkes \& Westwood, 2017; McConnell, Margalit, Malhotra, \& Levendusky, 2018). Research on partisanship has mostly underlined the negative effects it might have on citizens' decision making and attitudes toward political out-groups (Bolsen, Druckman, \& Cook, 2014; Gaines, Kuklinski, Quirk, Peyton, \& Verkuilen, 2007; Miller \& Conover, 2015; Taber \& Lodge, 2006). Yet, surprisingly little attention seems to be given to the role partisanship might play in shaping politicians' own attitudes and behaviours, including their conduct in office, perhaps due to the great difficulty of recruiting politicians for research (Caprara \& Zimbardo, 2004). We rely on a unique sample of active political party members to examine predictors of politicians' self-reported performance in their political work (Silvester, Wyatt, \& Randall, 2014), their political skill — the ability to achieve one's goals by acting politically (Ferris et al., 2005), and also intragroup behavioural intentions (volunteering and party loyalty). In this study, we will examine whether these aspects of political work are related to different ways politicians identify with their party.

\section{Political Work}

The first aspect of political work we focus on is political skill. Although obviously relevant to political work, political skill has originally been studied in the context of business organisations (Ferris et al., 2008). Political skill has been defined as the "ability to effectively understand others at work, and to use such knowledge to influence others to act in ways that enhance one's personal and/or organizational objectives" (Ahearn et al., 2004, p. 311). It is based on the assumption that workplaces and companies are inherently political environments 
(Mintzberg, 1983; Pfeffer, 1981). From this view, political behaviour at work is not problematic, but rather a natural and integral part of working in organisations (Silvester \& Wyatt, 2018). In fact, many jobs explicitly require political tactics, such as influencing or persuading others, making deals, mediating conflict and negotiating between competing sides.

Ferris and colleagues (2005) designed the Political Skill Inventory, which consists of four dimensions that capture distinctive skills, but may also reflect a single higher orderfactor of general political skill. Social astuteness encompasses both self-awareness and deep understanding of social interactions. Individuals high on interpersonal influence are able to adapt their behaviour to different contexts in order to better influence others in a subtle and convincing manner. Networking ability involves being able to form relationships with other people in order to attain personal or organisational goals, such as making deals and managing conflict. Last, apparent sincerity refers to political actors as being perceived by others as acquiring integrity, authenticity, sincerity, and overall strike people as genuine. Ferris and colleagues argue that apparent sincerity generates support and trust, but influence attempts fail when the target perceives the influencer to have ulterior motives or hidden agendas.

Political skill offers a measure of how successfully individuals perceive themselves to navigate a political environment. Political skill is not synonymous with good performance, although there is fairly robust evidence that they are positively related (see Munyon et al., 2015). Political skill has been found to predict job performance and effectiveness ratings among supervisors (Ferris et al., 2005), even after controlling for leaders' experience, team members' experience, and team empowerment (Ahearn et al., 2004). Some even argue that political skill is one of the most important competencies of leaders, as it has been found to facilitate employees' perception of organisational support, trust in management, organisational commitment, and other important indicators for organisations (Treadway et al., 
2004). Politically skilled leaders appear not only to be more effective, but their followers and subordinates become more effective too, through enhanced quality of their leader-follower relationships (Brouer, Douglas, Treadway, \& Ferris, 2013). The link between political skill and high performance in the job seems to be driven by social effectiveness, that is, politically skilled individuals knowing what to do in different circumstances, and knowing how to do it (Ferris et al., 2008). Underlining this, meta-analytic evidence (Bing, Davison, Minor, Novicevic, \& Frink, 2011) posits that political skill is more important for good performance in jobs with higher demands for social interactions. In other words, political skill is imperative for jobs that entail multiple and complex interpersonal relationships, such as working as a politician.

Indeed, the results of many studies conducted in the organisational context could generalise to the political party context. For example, politically skilled individuals have been found to be more effective in using impression and reputation management tactics (Blickle, Schneider, Liu, \& Ferris, 2011; Maher, Gallagher, Rossi, Ferris, \& Perrewé, 2018). The ability to network and build coalitions of support leads to better career and leadership outcomes (Wei, Chiang, \& Wu, 2012). In this way, political skill enables workers to successfully navigate their organisational environment and climb the organisational ladder (Munyon et al., 2015).

Politicians' performance is difficult to assess. One important indicator is an objective electoral outcome. However, since electoral systems vary considerably, it can be difficult to operationalise. To address the lack of defined performance constructs, Silvester and colleagues (2014) designed the Political Performance Questionnaire as an alternative measure of politicians' success. They set out to examine whether politicians shared a latent model of behaviours associated with political performance. Factor analyses revealed five dimensions of politicians' self-rated performance. The first performance variable, resilience, reflects a 
politician's ability to meet the demands of their job, such as balancing work and personal life, keeping up to date with constituents' concerns, and keeping up with developments in the community. Politicking refers to a politician's readiness to engage in secrecy, deception and political blood-sport. Analytical skill refers to the ability to understand complex information. The factor termed representing people entails campaigning for constituents, communicating values, and thus being recognised in the community. The fifth and last factor, relating to others, captures traits such as empathy, listening skills, and being approachable.

While political skill and political performance are conceptually related, they tap into different behaviours and their statistical relationship appears to be modest. In Silvester and colleagues' (2014) paper, political skill only emerged as a predictor of representing people and relating to others in regression analyses. Politicking exhibited correlations with higher Machiavellianism and lower agreeableness, but was unrelated to political skill. Politicking can also be described as the reversal of integrity (Wyatt \& Silvester, 2018).

A third aspect of politicians' work is participating in party activities and loyalty to the party, which we refer to collectively as intragroup behavioural intentions. It is important for the betterment of the party as a group that its candidates participate in everyday business of the grassroot and intend to stay with the party. We include two measures of such behavioural intentions in party activities: a measure of self-reported time spent volunteering for the party, and intentions to leave the party in the future.

In sum, in this project, we aim to investigate how the way politicians identify with their political party might be linked to their 1) political skill set, 2) performance in their political role and 3) intragroup behavioural intentions.

\section{Types of In-group Identity and Work-related Outcomes}

Research conducted predominantly in the business context suggests that one important determinant of work-related outcomes is identification with one's organisation, that 
is feeling part of the organisation and evaluating it positively (Leach et al., 2008; Tajfel, 1978). Here, we adopt this definition for partisan identification. Organisational identification correlates with positive outcomes in the workplace, including higher job satisfaction and lower turnover intentions (Riketta, 2005). Perhaps more relevant to politician's skill and performance, meta-analytic evidence has found organisational identification be associated with greater job performance (Riketta, 2005). One explanation for why this is the case may be that identification is linked to increased work motivation (Van Knippenberg, 2000), organisational citizenship behaviour, and readiness to cooperate (Dukerich, Golden, \& Shortell, 2002). Organisational identification, therefore, appears to nurture a concern for the organisation's general welfare and motivates better performance. Similarly to organisational identification, we could anticipate partisan identification to be associated with enhanced performance in the political arena.

However, people can identify with their social groups, including their organisations and political parties, in different ways. Recent research indicates that it is important to differentiate positive in-group identification from collective narcissism - a defensive ingroup identity that can have potentially problematic consequences both for relations within and between groups (Cichocka, 2016; Cichocka \& Cislak, 2020). Collective narcissism is a belief in the greatness of one's in-group that is not recognised by others (Golec de Zavala, Cichocka, Eidelson, \& Jayawickreme, 2009). It increases when people's feelings of autonomy and self-worth are threatened (Cichocka et al., 2018; Golec de Zavala et al., 2020)_people might compensate for frustrated personal needs by investing in the in-group image. This is likely why collective narcissists are more concerned with how the in-group reflects on them, rather than with the welfare of other group members (Cichocka, 2016). There is preliminary evidence that collective narcissism is associated with undesirable intragroup outcomes. For example, collective narcissism has been associated with 
undesirable social relations within organisations (Cichocka, 2016). In the national context, collective narcissism is linked to support for policies that can harm the nation in the long run (e.g., anti-conservation or anti-vaccination policies), as long as these policies make the group appear strong and resistant to external pressures (Cislak et al., 2020; Cislak, Wojcik, \& Cichocka, 2018). Here, we focus on partisan narcissism - that is collective narcissism measured in relation to the one's political party, and compare its effects to those of conventional partisan identification.

To date, there is little evidence for how politician's party identification might impact their work outcomes. However, the partisanship literature is vehement in that high partisan identification damages citizens' information processing and causes motivated reasoning (Taber \& Lodge, 2006). For example, studies have shown partisans are willing to abandon their ideological principles (Bolsen et al., 2014). Partisanship hinders collaboration among citizens in non-political tasks (McConnell et al., 2018) and partisan animosity can even be described as a form of prejudice (Lelkes \& Westwood, 2017). Here, however, we examine partisan identification and partisan narcissism as predictors of politicians' work related behaviours, rather than partisans' attitudes.

\section{Partisanship and Political Work}

We propose that partisanship could emerge as an important predictor of conduct in political work. While political skill has been linked to personality traits (like conscientiousness, self-monitoring, or emotional intelligence, Ferris et al., 2007), it can also be acquired by socialisation or mentoring (Blass, Brouer, Perrewé, \& Ferris, 2007; Lankau \& Scandura, 2002). Political parties are by nature social entities where active members undergo considerable socialisation and mentoring, where they learn the "know-how" of how things really work (Cooper-Thomas, 2015). For active politicians, party identity is likely to be different to the identity of ordinary voters who passively support their party from a distance. 
Instead, it could serve as an important organisational identity (cf. Greene, 2004), similar to workers in conventional workplaces (Riketta, 2005). We propose that these can result in different ways partisans feel about their party (i.e., partisan identification and partisan narcissism), which in turn are linked to political skill, performance and intragroup behavioural intentions, independently of the length of political socialisation (Van Knippenberg, 2000; Wegge et al., 2006).

We expect identification with the political party to be differentially associated with behaviours linked with high performance in a political role, as measured by the Political Performance Questionnaire (Silvester et al., 2014). This should be the case for both the more instinctive parts of the job, like being receptive of other people's points of view (relating to others) and communicating with one's constituents (representing people), but also more formal parts, like the review of a large amount of documents (analytical skills) and performing well under pressure (resilience). The same logic applies to the political skill-set. Politically skilled individuals are described as being self-confident, rather than self-absorbed, and as such, having an outward focus rather than inward and self-centred (Ferris et al., 2005). In other words, politically skilled people have a healthy self-esteem and show concern for others in their organisation (Brouer et al., 2013). Similarly, individuals that identify strongly with their organisation seem to have greater concern for their fellow co-workers (Cichocka, 2016). We therefore expect partisan identification to be associated with higher scores of social astuteness, networking ability, interpersonal influence, and apparent sincerity. Equally, high partisan identifiers should be more loyal to the party (Ellemers, Spears, \& Doosje, 1997; Marchlewska, Cichocka, Jaworska, Golec de Zavala, \& Bilewicz, 2020; Randsley de Moura, Abrams, Retter, Gunnarsdottir, \& Ando, 2009; Van Dick et al., 2004) and more keen on engaging in volunteering within party institutions (Greene, 2004). 
Partisan narcissism, in contrast, is likely to be associated with different outcomes. We do not necessarily expect partisan narcissism to be predictive of lower political skills or performance. Rather, partisan narcissism may predict different skills than partisan identification. Compared to the other outcome variables, politicking entails somewhat different qualities. For example, Silvester and colleagues (2014) found that it correlated negatively with resilience, analytical skills, and relating to others. It was also positively associated with Machiavellianism, but negatively related to agreeableness. Meanwhile, collective narcissism has exhibited positive relationships with negative emotionality (Golec de Zavala, 2019), individual narcissism, and psychological entitlement (Golec de Zavala et al., 2009). Some preliminary evidence suggests collective narcissists tend to exploit their coworkers (Cichocka, 2016). Thus, we argue that those scoring high in partisan narcissism might resolve to politicking in situations where secrecy and conflict are deemed permissible in order to achieve either a political or personal goal.

We expect those high in partisan narcissism not only to have a different skill-set to high partisan identifiers, but also to display different intragroup behavioural intentions. In the context of national in-groups, collective narcissism has been associated with greater readiness to leave one's homeland and move abroad for financial gains (Marchlewska et al., 2020). In contrast, high identifiers remain loyal to the group (Ellemers et al., 1997). We then expected that partisan narcissism predicts intentions to leave the party in the future. The opposite should be true for identification. As collective narcissists are more concerned with how the ingroup image reflects on them than with benefiting the ingroup and its members (Cichocka, 2016), we expect those high in partisan narcissism to spend less time volunteering for the party.

\section{The Present Study}


In this present paper, we integrate research and theorising from social and organisational psychology as well as political science. We examine whether partisan narcissism versus partisan identification predict the use of different strategies among politicians, namely, self-rated political skills and performance. We also utilise measures of volunteering in party activities and intentions to defect from the party in the future. To this end, we use a unique sample of Icelandic political elite members who ran for public office in elections taking place from 2013-17. Politicians are notoriously difficult to recruit for research (Caprara \& Zimbardo, 2004), and therefore, this sample presents a rare opportunity to get a "up-close" account of politicians" self-reported behaviours, rather than "at-adistance" measures where voters, the public or experts draw inferences, as most previous studies have relied on (Silvester et al., 2014).

We expect that partisan identification will predict higher self-reported scores of total political skill (H1a), as well as its subscales: networking ability (H1b), interpersonal influence (H1c), social astuteness (H1d), and apparent sincerity (H1e). Furthermore, we predict that partisan identification will be positively related to performance variables in terms of resilience (H2a), analytical skill (H2b), representing people (H2c), and relating to others (H2d). Last, we predict that partisan narcissism will be positively associated with higher levels of self-reported politicking behaviour (H2e). As for intragroup behavioural intentions, we hypothesise that partisan identification will predict more time spent volunteering $(\mathrm{H} 3 \mathrm{a})$ and lower levels of intentions to leave the party (H3b), while partisan narcissism should be related to less time in volunteering $(\mathrm{H} 3 \mathrm{c})$ and higher intentions to leave the party $(\mathrm{H} 3 \mathrm{~d})$.

To control for the possible confounding effects of socialisation, a separate set in analyses controls for tenure, that is years active in the party.

\section{Method}

\section{Participants and Recruitment}


This study relied on a sample of elite members of the Left-Green Party (commonly referred to as The Left-Greens), a left-wing political party in Iceland. The Left-Greens are the country's second biggest political party as of the elections of 2017 and lead the current government coalition. A total of 214 participants completed an online survey in part or in full. All materials were in the Icelandic language, translated by one of the researchers. The translations were reviewed by professionals in survey designs. Mean age of participants was 48.53 years $(S D=13.91)$, and $53.66 \%$ were female (coded as 2$), 45.85 \%$ male (coded as 1$)$, and one participant $(0.49 \%)$ identified as another gender.

The Icelandic voting system is based on party-list proportional representation. In parliamentary and municipal elections, parties put forward lists in each constituency with double the number of members of parliament or municipal council that are to be elected from the respective constituency. The Left-Greens' lists were accessed through the Ministry of the Interior's archives (www.kosning.is). All candidates in the parliamentary elections of 2013, 2016, 2017, and municipal elections of 2014, were contacted via telephone and offered to participate in an online survey. In total, 388 candidates participated in the aforementioned elections. By the time of data collection, 19 candidates had left the party and five had passed away. Sixty-seven candidates did not reply to two telephone calls or their telephone numbers could not be found, and 12 candidates refused to participate. Two-hundred eighty-five agreed to participate, and 245 started the online survey. Participants that gave a full response to at least one scale were retained for further analysis. In total, 31 participants $(12.65 \%)$ were excluded from further analysis due to missing data, leaving 214 participants (59\% of the available population) in the final dataset. Data collection took place from November 2017 to February 2018. No compensation was offered for participation. The data set has also been used in a separate paper (BLINDED), focusing on a different set of outcomes.

\section{Measures}


Partisan narcissism. Partisan narcissism was measured using the Collective Narcissism Scale (Golec de Zavala et al., 2009). The scale was adapted to mention the ingroup in question, the Left-Greens. For example, the scale included questions like "I wish that other political parties would more quickly recognise the authority of the Left-Greens" and "I insist upon the Left-Greens getting the respect they are due". The scale demonstrated good reliability (9 items, Cronbach's $\alpha=.81$ ). Answers were on a scale from 1 (strongly disagree) to 7 (strongly agree).

Partisan identification with the Left Greens was measured using the Social Identification Scale by Cameron (2004). The total score of the scale was computed by combining the three subscales ${ }^{1}$ of the scale. In-group ties were measured with items like "I have a lot in common with other members of the Left-Greens", centrality with items like "I often think about the fact that I am a member of the Left-Greens", and in-group affect with items like "In general, I'm glad to be a member of the Left-Greens". Participants responded on a scale from 1 (strongly disagree) to 7 (strongly agree). The scale exhibited good internal consistency (12 items, Cronbach's $\alpha=.81$ ).

Political skill was measured with the Political Skill Inventory (Ferris et al., 2005). In the following sections, both the inventory's total score and its four subscales was analysed. The 18 -item total score yielded high reliability $(\alpha=.90)$. The items were adapted to reflect the political nature of participants' work, as many will hold down jobs outside of politics as well. For example, networking ability was measured with questions such as: "I spend a lot of time and effort in my political work networking with others" ( 6 items, $\alpha=.90)$. Interpersonal influence was measured with items such as: "I am able to make most people feel comfortable and at ease around me" (4 items, $\alpha=.87)$. Social astuteness included items such as: "I am particularly good at sensing the motivations and hidden agendas of others" ( 5 items, $\alpha=.74$ ).

\footnotetext{
${ }^{1}$ Analyses for each subscale treated separately can be found in online Supplement.
} 
Apparent sincerity was measured with items such as: "When communicating with others, I try to be genuine in what I say and do" ( 3 items, $\alpha=.69)$. Answers were on a scale from 1 (strongly disagree) to 7 (strongly agree).

Political performance was measured with the Political Performance Questionnaire (Silvester et al., 2014). It has five subscales, all of which exhibited acceptable reliabilities in this study. Resilience was measured with items such as: "There is frequently too much going on in the community to keep up with" (reversed, 5 items, $\alpha=.77$ ). Politicking was measured with items such as "Sometimes there is a need for secrecy when making decisions" (5 items, $\alpha=.76$ ). Analytical skills were measured with items such as: "I find it easy to deal with complicated information" ( 4 items, $\alpha=.71$ ). Representing people was measured with items such as: "I am easily recognised by my constituents" ( 4 items, $\alpha=.74)$. Relating to others was measured with items such as "Others see me as someone who is easy to approach" (3 items, $\alpha=.79$ ). Answers were on a scale from 1 (strongly disagree) to 7 (strongly agree).

Volunteering. Participants were asked how many hours they volunteered for the party under two circumstances, during election campaigns $(M=18.10, S D=12.76)$ and outside of election campaigns $(M=4.95, S D=7.89)$. The two correlated moderately, $r(202)$ $=.39, p<.001$. These two items were averaged to reflect a global score of volunteering $(M=11.48, S D=8.70)$.

Intentions to leave the party. Participants were asked to indicate on a scale of 1 to 7 , how much they agreed with the statement "I might leave from the Left-Greens sometime in the future" $(M=3.70, S D=1.99)$.

Tenure in the party. Participants were asked which year they became members of the Left-Greens $(1999$ - 2017). This question was used to compute a variable for tenure in party, measured as years since joining. This variable is used as a control variable in regression analyses. 


\section{Results}

Correlations and descriptive statistics are displayed in Table 1. Some notable correlations emerged between the predictors and outcome variables. For political skills, partisan identification was associated with higher levels of networking ability, interpersonal influence, social astuteness, and apparent sincerity. It was also positively correlated with total political skill, $r(210)=.33, p<.001$. In terms of political performance, partisan identification was significantly positively correlated with analytical skills and representing others. Partisan narcissism was only significantly positively correlated with politicking and networking ability. Partisan narcissism marginally, $r(204)=.13, p=.059$, correlated with total political skill.

Partisan identification was positively associated with volunteering. Both partisan identification and partisan narcissism were negatively associated with intention to leave the party, albeit the effect for partisan identification was about twice as large as for partisan narcissism.

\section{-- INSERT TABLE 1 HERE -}

To test the hypotheses, partisan narcissism and partisan identification were entered simultaneously as predictors in separate regression models for each dependent variable (with pairwise exclusions for missing data). Gender and age were also added as control variables. Regression models for political skills as dependent variables are presented in Table 2. First, partisan identification emerged as a significant, positive predictor of total political skill score $(\beta=.31 p<.001)$, while partisan narcissism was not significantly related to political skill $(\beta=$ $.04, p=.60)$. We then tested for the models for each individual subscale. Partisan identification was a significant, positive predictor of networking ability $(\beta=.30, p<.001)$, interpersonal influence $(\beta=.17, p=.02)$, social astuteness $(\beta=.24, p=.002)$, and apparent sincerity $(\beta=.18, p<.001)$. Partisan narcissism was not related to any of the facets of 
political skill. Partisan identification did negatively predict total political skill $(\beta=-.15, p=$ $.04)$, interpersonal influence $(\beta=-.17, p=.02)$, and apparent sincerity $(\beta=-.19, p=.006)$.

\section{-- INSERT TABLE 2 HERE -}

Regression analyses for political performance are presented in Table 3. Each political performance variable was entered in a regression model, with partisan narcissism and partisan identification as predictors, and gender and age as controls. We found no significant effects for resilience, although partisan identification was marginally, positively predictive $(\beta$ $=.13, p=.09)$. Partisan narcissism was a significant, positive, predictor of politicking $(\beta=$ $.16, p=.02)$. Partisan identification positively predicted analytical skill $(\beta=.24, p=.001)$. and representing people $(\beta=.20, p<.001)$.

\section{-- INSERT TABLE 3 HERE --}

Regression analyses for intragroup behavioural intentions variables can be found in Table 4. Partisan identification emerged as a significant, positive, predictor of volunteering ${ }^{2}$ $(\beta=.22, p=.003)$, while partisan narcissism was not $(\beta=-.03, p=.68)$. Partisan identification was a significant, negative predictor of intentions to leave the party in the future $(\beta=-.38, p<.001)$, while partisan narcissism was not a significant predictor $(\beta=-.00$, $p=.17)$.

\section{-- INSERT TABLE 4 HERE -}

We repeated the above analyses with tenure as a control variable. We chose to include tenure in a separate set of analyses as this variable had a lot of missing data, mostly due to participants not being sure which exact year they joined the party. Regression analyses can be found in the Supplement. Pattern of results remained the same for all dependent variables,

\footnotetext{
${ }^{2}$ The volunteering variable was highly skewed, with most participants reporting few hours. We therefore also repeated our regression analysis with 5,000 bootstrap samples to substantiate the results reported above. Pattern of results remained the same.
} 
except for "representing people", in which case the regression equation became insignificant, possibly due to data attrition.

\section{Discussion}

We examined the associations different modes of partisanship have with politicians self-reported skills and behaviours. We hypothesised that partisan narcissism and partisan identification would differentially predict political skill, performance and intragroup behavioural intentions. The results supported most of our hypotheses. Partisan identification was positively associated with better political skills overall (in line with H1a), and all of its sub-dimensions (H1b-H1e). Partisan identification also predicted higher political performance, in terms of analytical skills $(\mathrm{H} 2 \mathrm{~b})$ and representing people $(\mathrm{H} 2 \mathrm{c})$. However, partisan identification was not significantly associated with resilience or relating to others, failing to support $\mathrm{H} 2 \mathrm{a}$ and $\mathrm{H} 2 \mathrm{~d}$, respectively. As hypothesised, partisan narcissism positively predicted politicking (H2e). Partisan identification predicted more time spent volunteering (H3a) and lower levels of intentions to leave the party (H3b). Partisan narcissism did not show the hypothesised opposing relationships (H3c and H3d).

This research contributes to the literature in several ways. First, few studies to date have examined the conduct of politicians as political workers (cf. Silvester et al., 2014; Silvester \& Dykes, 2007). This is likely due to great difficulty of recruiting politicians for research (Caprara \& Zimbardo, 2004). We contacted almost every candidate running in the aforementioned period by phone and subsequently by email, which yielded a great response rate. Our sample can be considered close to representative for the Left-Green party as it entails over half of the population (59\%) of party members actively seeking political office. Also, because the full sample comes from a single political party, we were able to hold factors such as political ideology and party norms constant. Thus, by relying on a sample of 
elite political party members, our study offered a unique opportunity to examine the role of partisanship in political work.

Second, we integrate research on group identity from social and organisational psychology with research on partisanship from political science. A large literature suggests that strong organisational identification can yield positive outcomes for the organisation and the individual worker (Riketta, 2005; Wegge et al., 2006). Social psychological research conceptualising partisanship as a meaningful psychological attachment to a group, not just as an attitude towards a party, have reached similar conclusions (cf. Greene, 2004). Meanwhile, the partisanship literature is near unanimous in the conclusion that political party identification has negative outcomes - by affecting information processing and decisionmaking among citizens (Bolsen et al., 2014; Taber \& Lodge, 2006). In contrast, our findings suggest that strong partisanship among political actors may be associated with positive outcomes, such as increased professionalism and better governance.

We found that high partisan identifiers reported skills that facilitate trust, support, and perception of sincerity in their attempt to obtain their goals (Ferris et al., 2005). Furthermore, we demonstrated that partisan identification can be associated with positive effects beyond the in-group (i.e., the political party) itself. Partisan identification positively predicted representing others, that is one's constituents and the electorate at large. This suggests that partisan identification might facilitate representing a wider group of people, such as one's constituency or country, rather than just one's own goals or your party's agenda. Thus, partisanship, at least in its non-narcissistic form, is not necessarily incompatible with “statesmanship” (Cichocka, 2016; Golec de Zavala, Cichocka, \& Bilewicz, 2013).

The present results also shed light on social identification as a form of genuine ingroup identification in terms of group activities. Partisan identification predicted higher selfreported levels of volunteering for the party and lower intentions to leave the party. This is 
consistent with research showing the benefits of organisational identification in the business context (see e.g., Abrams, Ando, \& Hinkle, 1998; Riketta, 2005). Both of these variables can be viewed as important for the future health and functioning of an organisation.

Finally, our research contributed to the growing literature on collective narcissism. Past studies mostly focused on collective narcissism in the national context (e.g., Cichocka \& Cislak, 2020), only occasionally applying it to other groups, including gender (Górska et al., 2020) and business (Cichocka, 2016), religious (Marchlewska, Cichocka, Łozowski, Górska, \& Winiewski, 2019) or extremist (Jasko et al., 2020) organisations. Here, we examine the role of collective narcissism within the political party context. Given the conflict driven, and often hostile, inter- and intragroup dynamics in politics, partisan narcissism seems to be an important factor to consider in research on partisanship.

While their highly identified colleagues embraced networking, appeared sincere and strived to represent others, those high in partisan narcissism were more likely to engage in politicking, the inclination to engage in secrecy, deception, and political blood-sport, seemingly without other accompanying skills or self-assessment of political performance. Politicking is the opposite of integrity (Wyatt \& Silvester, 2018), so our paper demonstrates that collective narcissism is negatively related to integrity in an organisational setting. It is also consistent with research highlighting the negative effects of collective narcissism both for intra- and intergroup relations (Cichocka, 2016). For example, recent studies showed that national narcissism was associated with readiness to potentially harm own citizens by engaging in conspiracies against them (Biddlestone, Cichocka, Glowczewski, \& Cislak, 2020). This is likely because collective narcissism is linked to using the group for personal benefits, rather than on caring for or working with other group members.

We did not find the predicted relationships between partisan narcissism and intragroup behavioural intentions - it neither predicted time spent volunteering, nor 
intentions to leave the party. This is possibly due to our study not offering any personal benefits with leaving, as has been done in previous studies (Marchlewska et al., 2020). Collective narcissist's ingroup loyalty may be dependent on what benefits group membership brings at any given time. If the grass is not greener on the other side, one might as well stay where one is currently.

\section{Limitations and Future Research}

Our data was cross-sectional, so causality cannot be established. Although we considered partisan identification and narcissism as predictors, it is possible to speculate that a high political skill set and good performance in a political role actually builds identification with one's party. We also relied on-self report data, not other-rated skills and performance as some previous studies of political skill and performance (Ahearn et al., 2004; Silvester et al., 2014). Perception is a key element in political skill, that is, being perceived as sincere and genuine, and without any ulterior or self-serving motives (Ferris et al., 2007). However, past work has shown positive associations between political skill, as assessed by co-workers, with actual performance in work setting (Blickle, Ferris, et al., 2011). Still, it would be useful for future research to get externally reported assessments of political skill and performance and link them with self-rated partisanship.

The present study can be fruitful for the literature on in-group identification and its consequences for the in-group. Differentiating the effects of collective narcissism may help explain why strong identity is sometimes associated with harmful outcomes. For example, in the organisational context, research has demonstrated that high identification can lead to unethical but pro-organisational behaviour, such as lying to customers to increase sales (Chen, Chen, \& Sheldon, 2016). Unethical pro-organisational behaviour may resemble politicking in the sense of striving to attend a common goal with little regard to the way the 
goal is attained. Future research should directly address the link between organisational narcissism and superficially pro-organisational, and yet maladaptive, outcomes.

Future studies should also investigate long-term performance outcomes. For example, it is uncertain how politicking works as a strategy. Even though it is reasonable to assume that it is a behaviour with some negative social consequences, it is possible that overtime this type of skill is more effective because those individuals are able to push things through to achieve change, whereas politicians who do not engage in politicking may struggle to get their policies fulfilled (Wyatt \& Silvester, 2018). In other words, it is possible politicking may be essential in "getting things done" in the political arena, like getting legislation through parliament and policies implemented.

Last, our study relied on a sample recruited from a left-wing party, in a homogeneous country in Northern Europe. While we would expect the relationships exhibited here to generalise across different parties and organisations, they could also be a product of cultural and political contexts. Future studies should therefore strive to examine partisan narcissism on the right-wing of the political spectrum, and in different cultural contexts.

\section{Conclusions}

Stereotypes about political behaviour generally portray it as malevolent or problematic but, as scholars have pointed out, politics is work for politicians (Silvester \& Wyatt, 2018). As such, the competitive and ambiguous work that environment politicians face is deserving of more research attention. In our study, different modes of partisanship were associated with different work behaviours in a sample of politicians. We conclude that partisan identity can be linked to constructive conduct of politicians. Partisan narcissism, in contrast, seems rather to be associated with more devious work habits that many find stereotypical of politicians. 


\section{References}

Abrams, D., Ando, K., \& Hinkle, S. (1998). Psychological attachment to the group: Crosscultural differences in organizational identification and subjective norms as predictors of workers' turnover intentions. Personality and Social Psychology Bulletin, 24(10), 1027-1039. https://doi.org/10.1177/01461672982410001

Ahearn, K. K., Ferris, G. R., Hochwarter, W. A., Douglas, C., \& Ammeter, A. P. (2004). Leader political skill and team performance. Journal of Management, 30(3), 309-327. https://doi.org/10.1016/j.jm.2003.01.004

Biddlestone, M., Cichocka, A., Glowczewski, M., \& Cislak, A. (2020, July). Their own worst enemy? Collective narcissists are willing to conspire against their ingroup. Paper presented at the Annual Meeting of the International Society for Political Psychology, Virtual conference.

Bing, M. N., Davison, H. K., Minor, I., Novicevic, M. M., \& Frink, D. D. (2011). The prediction of task and contextual performance by political skill: A meta-analysis and moderator test. Journal of Vocational Behavior, 79(2), 563-577. https://doi.org/10.1016/j.jvb.2011.02.006

Blass, F. R., Brouer, R. L., Perrewé, P. L., \& Ferris, G. R. (2007). Politics understanding and networking ability as a function of mentoring: The roles of gender and race. Journal of Leadership \& Organizational Studies. (Sage CA: Los Angeles, CA). https://doi.org/10.1177/1071791907308054

Blickle, G., Ferris, G. R., Munyon, T. P., Momm, T., Zettler, I., Schneider, P. B., \& Buckley, M. R. (2011). A multi-source, multi-study investigation of job performance prediction by political skill. Applied Psychology, 60(3), 449-474. https://doi.org/10.1111/j.14640597.2011.00443.x 
Blickle, G., Schneider, P. B., Liu, Y., \& Ferris, G. R. (2011). A predictive investigation of reputation as mediator of the political-skill/career-success relationship. Journal of Applied Social Psychology, 41(12), 3026-3048. https://doi.org/10.1111/j.15591816.2011.00862.x

Bolsen, T., Druckman, J. N., \& Cook, F. L. (2014). The influence of partisan motivated reasoning on public opinion. Political Behavior, 36(2), 235-262. https://doi.org/10.1007/s11109-013-9238-0

Brouer, R. L., Douglas, C., Treadway, D. C., \& Ferris, G. R. (2013). Leader political skill, relationship quality, and leadership effectiveness: A two-study model test and constructive replication. Journal of Leadership \& Organizational Studies, 20(2), 185198. https://doi.org/10.1177/1548051812460099

Bump, P. (2019, October 11). The partisan divide keeps growing. Retrieved 1 June 2020, from Washington Post website: https://www.washingtonpost.com/politics/2019/10/11/partisan-divide-keeps-growing/

Caprara, G. V., \& Zimbardo, P. G. (2004). Personalizing politics: A congruency model of political preference. American Psychologist, 59(7), 581-594. https://doi.org/10.1037/0003-066X.59.7.581

Chen, M., Chen, C. C., \& Sheldon, O. J. (2016). Relaxing moral reasoning to win: How organizational identification relates to unethical pro-organizational behavior. Journal of Applied Psychology, 101(8), 1082-1096. https://doi.org/10.1037/ap10000111

Cichocka, A. (2016). Understanding defensive and secure in-group positivity: The role of collective narcissism. European Review of Social Psychology, 27(1), 283-317. https://doi.org/10.1080/10463283.2016.1252530

Cichocka, A., \& Cislak, A. (2020). Nationalism as collective narcissism. Current Opinion in Behavioral Sciences, 34, 69-74. https://doi.org/10.1016/j.cobeha.2019.12.013 
Cichocka, A., Golec de Zavala, A., Marchlewska, M., Bilewicz, M., Jaworska, M., \& Olechowski, M. (2018). Personal control decreases narcissistic but increases nonnarcissistic in-group positivity. Journal of Personality, 86(3), 465-480. https://doi.org/10.1111/jopy.12328

Cislak, A., Marchlewska, M., Wojcik, A. D., Śliwiński, K., Molenda, Z., Szczepańska, D., \& Cichocka, A. (2020). National narcissism and support for voluntary vaccination policy: The mediating role of vaccination conspiracy beliefs. Group Processes \& Intergroup Relations, in press.

Cislak, A., Wojcik, A. D., \& Cichocka, A. (2018). Cutting the forest down to save your face: Narcissistic national identification predicts support for anti-conservation policies. Journal of Environmental Psychology, 59, 65-73. https://doi.org/10.1016/j.jenvp.2018.08.009

Cooper-Thomas, H. (2015). Becoming an MP. The Psychologist, 28(5), 364-367.

Drutman, L. (2017, September 5). The new breed of hyperpartisanship could destroy American democracy. Retrieved 2 June 2020, from Vox website: https://www.vox.com/the-big-idea/2017/9/5/16227700/hyperpartisanship-identityamerican-democracy-problems-solutions-doom-loop

Dukerich, J. M., Golden, B. R., \& Shortell, S. M. (2002). Beauty is in the eye of the beholder: The impact of organizational identification, identity, and image on the cooperative behaviors of physicians. Administrative Science Quarterly, 47(3), 507-533. https://doi.org/10.2307/3094849

Ellemers, N., Spears, R., \& Doosje, B. (1997). Sticking together or falling apart: In-group identification as a psychological determinant of group commitment versus individual mobility. Journal of Personality and Social Psychology, 72(3), 617-626. https://doi.org/10.1037/0022-3514.72.3.617 
Ferris, G. R., Blickle, G., Schneider, P. B., Kramer, J., Zettler, I., Solga, J., .. Meurs, J. A. (2008). Political skill construct and criterion-related validation: A two-study investigation. Journal of Managerial Psychology, 23(7), 744-771. https://doi.org/10.1108/02683940810896321

Ferris, G. R., Treadway, D. C., Kolodinsky, R. W., Hochwarter, W. A., Kacmar, C. J., Douglas, C., \& Frink, D. D. (2005). Development and validation of the political skill inventory, development and validation of the political skill inventory. Journal of Management, 31(1), 126-152. https://doi.org/10.1177/0149206304271386

Gaines, B. J., Kuklinski, J. H., Quirk, P. J., Peyton, B., \& Verkuilen, J. (2007). Same facts, different interpretations: Partisan motivation and opinion on Iraq. The Journal of Politics, 69(4), 957-974. https://doi.org/10.1111/j.1468-2508.2007.00601.x

Gaskell, A. (2020, February 13). How partisanship is destroying America's competitiveness. Retrieved 1 June 2020, from Forbes website: https://www.forbes.com/sites/adigaskell/2020/02/13/how-partisanship-is-destroyingamericas-competitiveness/

Golec de Zavala, A. (2019). Collective narcissism and in-group satisfaction are associated with different emotional profiles and psychological wellbeing. Frontiers in Psychology, 10. https://doi.org/10.3389/fpsyg.2019.00203

Golec de Zavala, A., Cichocka, A., \& Bilewicz, M. (2013). The paradox of in-group love: Differentiating collective narcissism advances understanding of the relationship between in-group and out-group attitudes. Journal of Personality, 81(1), 16-28. https://doi.org/10.1111/j.1467-6494.2012.00779.x

Golec de Zavala, A., Cichocka, A., Eidelson, R., \& Jayawickreme, N. (2009). Collective narcissism and its social consequences. Journal of Personality and Social Psychology, 97(6), 1074-1096. https://doi.org/10.1037/a0016904 
Golec de Zavala, A., Federico, C. M., Sedikides, C., Guerra, R., Lantos, D., Mroziński, B., ... Baran, T. (2020). Low self-esteem predicts out-group derogation via collective narcissism, but this relationship is obscured by in-group satisfaction. Journal of Personality and Social Psychology, 119(3), 741-764.

https://doi.org/10.1037/pspp0000260

Górska, P., Stefaniak, A., Malinowska, K., Lipowska, K., Marchlewska, M., Budziszewska, M., \& Maciantowicz, O. (2020). Too great to act in solidarity: The negative relationship between collective narcissism and solidarity-based collective action. European Journal of Social Psychology, 50(3), 561-578. https://doi.org/10.1002/ejsp.2638

Greene, S. (2004). Social identity theory and party identification. Social Science Quarterly, 85(1), 136-153. https://doi.org/10.1111/j.0038-4941.2004.08501010.x

Jasko, K., Webber, D., Kruglanski, A. W., Gelfand, M., Taufiqurrohman, M., Hettiarachchi, M., \& Gunaratna, R. (2020). Social context moderates the effects of quest for significance on violent extremism. Journal of Personality and Social Psychology, 118(6), 1165-1187. https://doi.org/10.1037/pspi0000198

Lankau, M. J., \& Scandura, T. A. (2002). An investigation of personal learning in mentoring relationships: Content, antecedents, and consequences. Academy of Management Journal, 45(4), 779-790. https://doi.org/10.5465/3069311

Leach, C. W., van Zomeren, M., Zebel, S., Vliek, M. L. W., Pennekamp, S. F., Doosje, B., ... Spears, R. (2008). Group-level self-definition and self-investment: A hierarchical (multicomponent) model of in-group identification. Journal of Personality and Social Psychology, 95(1), 144-165. https://doi.org/10.1037/0022-3514.95.1.144

Lelkes, Y., \& Westwood, S. J. (2017). The limits of partisan prejudice. The Journal of Politics, 79(2), 485-501. https://doi.org/10.1086/688223 
Maher, L. P., Gallagher, V. C., Rossi, A. M., Ferris, G. R., \& Perrewé, P. L. (2018). Political skill and will as predictors of impression management frequency and style: A threestudy investigation. Journal of Vocational Behavior, 107, 276-294. https://doi.org/10.1016/j.jvb.2018.05.004

Marchlewska, M., Cichocka, A., Jaworska, M., Golec de Zavala, A., \& Bilewicz, M. (2020). Superficial ingroup love? Collective narcissism predicts ingroup image defense, outgroup prejudice, and lower ingroup loyalty. British Journal of Social Psychology, $n / a(\mathrm{n} / \mathrm{a})$. https://doi.org/10.1111/bjso.12367

Marchlewska, M., Cichocka, A., Łozowski, F., Górska, P., \& Winiewski, M. (2019). In search of an imaginary enemy: Catholic collective narcissism and the endorsement of gender conspiracy beliefs. The Journal of Social Psychology, 159(6), 766-779. https://doi.org/10.1080/00224545.2019.1586637

McConnell, C., Margalit, Y., Malhotra, N., \& Levendusky, M. (2018). The economic consequences of partisanship in a polarized era. American Journal of Political Science, 62(1), 5-18. https://doi.org/10.1111/ajps. 12330

Miller, P. R., \& Conover, P. J. (2015). Red and blue states of mind: Partisan hostility and voting in the United States. Political Research Quarterly, 68(2), 225-239. https://doi.org/10.1177/1065912915577208

Mintzberg, H. (1983). Power in and around organizations. Englewood Cliffs, NJ: Prentice Hall.

Munyon, T. P., Summers, J. K., Thompson, K. M., \& Ferris, G. R. (2015). Political skill and work outcomes: A theoretical extension, meta-analytic investigation, and agenda for the future. Personnel Psychology, 68(1), 143-184. https://doi.org/10.1111/peps.12066 Pfeffer, J. (1981). Power in organizations. Boston: Pitman. 
Randsley de Moura, G., Abrams, D., Retter, C., Gunnarsdottir, S., \& Ando, K. (2009). Identification as an organizational anchor: How identification and job satisfaction combine to predict turnover intention. European Journal of Social Psychology, 39(4), 540-557. https://doi.org/10.1002/ejsp.553

Riketta, M. (2005). Organizational identification: A meta-analysis. Journal of Vocational Behavior, 66(2), 358-384. https://doi.org/10.1016/j.jvb.2004.05.005

Silvester, J., \& Dykes, C. (2007). Selecting political candidates: A longitudinal study of assessment centre performance and political success in the 2005 UK General Election. Journal of Occupational and Organizational Psychology, 80(1), 11-25. https://doi.org/10.1348/096317906X156287

Silvester, J., \& Wyatt, M. (2018). Political effectiveness at work. In D. Ones, N. Anderson, C. Viswesvaran, \& H. K. Sinangil (Eds.), The SAGE Handbook of Industrial, Work \& Organizational Psychology. UK: Sage.

Silvester, J., Wyatt, M., \& Randall, R. (2014). Politician personality, Machiavellianism, and political skill as predictors of performance ratings in political roles. Journal of Occupational and Organizational Psychology, 87(2), 258-279. https://doi.org/10.1111/joop.12038

Taber, C. S., \& Lodge, M. (2006). Motivated skepticism in the evaluation of political beliefs. American Journal of Political Science, 50(3), 755-769. https://doi.org/10.1111/j.1540-5907.2006.00214.x

Tajfel, H. (Ed.). (1978). Differentiation between social groups: Studies in the social psychology of intergroup relations. Oxford, England: Academic Press.

Treadway, D. C., Hochwarter, W. A., Ferris, G. R., Kacmar, C. J., Douglas, C., Ammeter, A. P., \& Buckley, M. R. (2004). Leader political skill and employee reactions. The Leadership Quarterly, 15(4), 493-513. https://doi.org/10.1016/j.leaqua.2004.05.004 
Van Dick, R., Christ, O., Stellmacher, J., Wagner, U., Ahlswede, O., Grubba, C., ... Tissington, P. A. (2004). Should I stay or should I go? Explaining turnover intentions with organizational identification and job satisfaction. British Journal of Management, 15(4), 351-360. https://doi.org/10.1111/j.1467-8551.2004.00424.x

Van Knippenberg, D. (2000). Work motivation and performance: A social identity perspective. Applied Psychology, 49(3), 357-371. https://doi.org/10.1111/14640597.00020

Wegge, J., Dick, R. V., Fisher, G. K., Wecking, C., \& Moltzen, K. (2006). Work motivation, organisational identification, and well-being in call centre work. Work \& Stress, 20(1), 60-83. https://doi.org/10.1080/02678370600655553

Wei, L.-Q., Chiang, F. F. T., \& Wu, L.-Z. (2012). Developing and utilizing network resources: Roles of political skill. Journal of Management Studies, 49(2), 381-402. https://doi.org/10.1111/j.1467-6486.2010.00987.x

Wyatt, M., \& Silvester, J. (2018). Do voters get it right? A test of the ascription-actuality trait theory of leadership with political elites. The Leadership Quarterly, 29(5), 609-621. https://doi.org/10.1016/j.leaqua.2018.02.001 
Table 1

Descriptive Statistics and Bivariate Correlations Among Variables

\begin{tabular}{|c|c|c|c|c|c|c|c|c|c|c|c|c|c|c|}
\hline Variable & $M$ & $S D$ & 1 & 2 & 3 & 4 & 5 & 6 & 8 & 9 & 10 & 11 & 12 & 13 \\
\hline 1. Partisan narcissism & 3.92 & 0.96 & - & & & & & & & & & & & \\
\hline 2. Partisan identification & 5.09 & 0.84 & $.33 * * *$ & - & & & & & & & & & & \\
\hline 3. Networking ability & 4.12 & 1.28 & $.16^{*}$ & $.33 * * *$ & - & & & & & & & & & \\
\hline 4. Interp. influence & 5.59 & 0.87 & .02 & $.14^{*}$ & $.37 * * *$ & - & & & & & & & & \\
\hline 5. Social astuteness & 5.19 & 0.85 & .10 & $.25 * * *$ & $.54 * * *$ & $.59 * * *$ & - & & & & & & & \\
\hline 6. Apparent sincerity & 6.38 & 0.61 & .04 & $.21 * *$ & $.30 * * *$ & $.58 * * *$ & $.47 * * *$ & - & & & & & & \\
\hline 7. Resilience & 4.14 & 1.19 & -.03 & $.12^{+}$ & -.07 & -.12 & -.10 & $-.15^{*}$ & - & & & & & \\
\hline 8. Politicking & 3.26 & 1.27 & $.22 * *$ & .06 & $.18 * *$ & $-.17 *$ & .11 & $-.17 *$ & $-.12^{+}$ & - & & & & \\
\hline 9. Analytical skills & 4.79 & 1.06 & .02 & $.21 * *$ & $.36^{* * *}$ & $.24 * * *$ & $.33 * * *$ & $.15^{*}$ & $.18^{*}$ & $.16^{*}$ & - & & & \\
\hline 10. Relating to others & 5.33 & 1.08 & .10 & $.12^{+}$ & $.37 * * *$ & $.53 * * *$ & $.46^{* * *}$ & $.47 * * *$ & -.03 & $-.12^{+}$ & $.24 * * *$ & - & & \\
\hline 11. Rep. people & 4.39 & 0.96 & .11 & $.21 * *$ & $.47 * * *$ & $.52 * * *$ & $.45^{* * *}$ & $.36 * * *$ & $-.13^{+}$ & .06 & $.32 * * *$ & $.46^{* * *}$ & - & \\
\hline 12. Volunteering & 11.48 & 8.70 & .05 & $.20 * *$ & $.31 * * *$ & $.23 * * *$ & $.25 * * *$ & $.19 * *$ & -.11 & .10 & $.14^{+}$ & $.18^{*}$ & $.24 * * *$ & - \\
\hline 13. Intentions to leave & 3.70 & 1.99 & $-.19 * *$ & $-.42 * * *$ & $-.16^{*}$ & $.15^{*}$ & -.08 & -.08 & -.10 & -.07 & -.06 & .00 & $-.16^{*}$ & $-.15^{*}$ \\
\hline
\end{tabular}


Note. ${ }^{+} p<.10 .{ }^{* * *} p<.001 .{ }^{* *} p<.01 .{ }^{*} p<.05$. 
Table 2

Regression Analysis with Partisan Identification Variables as Predictors of Political Skill

\begin{tabular}{|c|c|c|c|c|c|c|c|c|c|c|c|c|c|c|c|}
\hline & \multicolumn{3}{|c|}{ Total Political Skill } & \multicolumn{3}{|c|}{ Networking Ability } & \multicolumn{3}{|c|}{ Interpersonal Influence } & \multicolumn{3}{|c|}{ Social Astuteness } & \multicolumn{3}{|c|}{ Apparent Sincerity } \\
\hline & $b$ & $S E$ & $\beta$ & $b$ & $S E$ & $\beta$ & $b$ & $S E$ & $\beta$ & $b$ & $S E$ & $\beta$ & $b$ & $S E$ & $\beta$ \\
\hline Partisan narcissism & 0.03 & 0.06 & .04 & 0.05 & 0.10 & .04 & 0.03 & 0.07 & .03 & 0.01 & 0.07 & .01 & 0.03 & 0.04 & .04 \\
\hline Partisan identification & $0.28 * * *$ & 0.07 & .31 & $0.46^{* * *}$ & 0.11 & .30 & $0.18 *$ & 0.08 & .17 & $0.24 * *$ & 0.08 & .24 & $0.18 * * *$ & 0.05 & .25 \\
\hline Age & $-0.01 *$ & 0.00 & -.16 & -0.01 & 0.01 & -.08 & $-0.01 *$ & 0.00 & -.17 & -0.01 & 0.00 & -.12 & $-0.01 * *$ & 0.00 & -.19 \\
\hline Gender $(1=\mathrm{M}, 2=\mathrm{F})$ & -0.01 & 0.11 & -.01 & -0.12 & 0.18 & -.05 & 0.19 & 0.12 & .11 & -0.08 & 0.12 & -.05 & $0.27 * *$ & 0.08 & .23 \\
\hline$F(d f)$ & \multicolumn{3}{|c|}{$5.75(4,186)^{* * *}$} & \multicolumn{3}{|c|}{$5.24(4,193)^{* * *}$} & \multicolumn{3}{|c|}{$3.58(4,193)^{* *}$} & \multicolumn{3}{|c|}{$3.20(4,190)^{*}$} & \multicolumn{3}{|c|}{$8.50(4,191)^{* * *}$} \\
\hline$R^{2}$ & \multicolumn{3}{|c|}{.11} & \multicolumn{3}{|c|}{.10} & \multicolumn{3}{|c|}{.07} & \multicolumn{3}{|c|}{.06} & \multicolumn{3}{|c|}{.15} \\
\hline Adjusted $R^{2}$ & \multicolumn{3}{|c|}{.09} & \multicolumn{3}{|c|}{.08} & \multicolumn{3}{|c|}{.05} & \multicolumn{3}{|c|}{.04} & \multicolumn{3}{|c|}{.13} \\
\hline
\end{tabular}

Note. ${ }^{*} p<.05 . * * p<.01 . * * * p<.001$. 
Table 3

Regression Analysis with Partisan Identification Variables as Predictors of Political Performance

\begin{tabular}{|c|c|c|c|c|c|c|c|c|c|c|c|c|c|c|c|}
\hline & \multicolumn{3}{|c|}{ Resilience } & \multicolumn{3}{|c|}{ Politicking } & \multicolumn{3}{|c|}{ Analytical Skills } & \multicolumn{3}{|c|}{ Representing People } & \multicolumn{3}{|c|}{ Relating to Others } \\
\hline & $b$ & $S E$ & $\beta$ & $b$ & $S E$ & $\beta$ & $b$ & $S E$ & $\beta$ & $b$ & $S E$ & $\beta$ & $b$ & $S E$ & $\beta$ \\
\hline Partisan narcissism & -0.14 & 0.09 & -.12 & $0.21 *$ & 0.09 & .16 & -0.10 & 0.08 & -.09 & 0.06 & 0.08 & .06 & 0.08 & 0.08 & .08 \\
\hline Partisan identification & $0.18^{+}$ & 0.10 & .13 & -0.02 & 0.11 & -.01 & $0.29 * *$ & 0.09 & .24 & $0.26^{* *}$ & 0.09 & .20 & 0.13 & 0.09 & .11 \\
\hline Age & $.01^{+}$ & 0.01 & .12 & 0.01 & 0.01 & .06 & $-0.01^{+}$ & 0.01 & -.13 & -0.00 & 0.01 & -.04 & $-0.01 *$ & 0.01 & -.16 \\
\hline Gender $(1=\mathrm{M}, 2=\mathrm{F})$ & -0.05 & 0.17 & -.02 & $-0.83 *$ & 0.17 & -.33 & $-0.41 * *$ & 0.15 & -.20 & -0.02 & 0.15 & -.01 & 0.15 & 0.14 & .08 \\
\hline$F(d f)$ & \multicolumn{3}{|c|}{$1.98(4,193)$} & \multicolumn{3}{|c|}{$9.17(4,192)^{* * *}$} & \multicolumn{3}{|c|}{$4.44(4,192)^{* *}$} & \multicolumn{3}{|c|}{$2.50(4,189)^{*}$} & \multicolumn{3}{|c|}{$2.44(4,189)^{*}$} \\
\hline$R^{2}$ & \multicolumn{3}{|c|}{.04} & \multicolumn{3}{|c|}{.16} & \multicolumn{3}{|c|}{.09} & \multicolumn{3}{|c|}{.05} & \multicolumn{3}{|c|}{0.05} \\
\hline Adjusted $R^{2}$ & \multicolumn{3}{|c|}{.02} & \multicolumn{3}{|c|}{.14} & \multicolumn{3}{|c|}{.07} & \multicolumn{3}{|c|}{.03} & \multicolumn{3}{|c|}{0.03} \\
\hline
\end{tabular}

Note. ${ }^{+} p<.10 .{ }^{*} p<.05 .{ }^{* *} p<.01 .{ }^{* * *} p<.001$ 
Table 4

Regression Analysis with Partisan Identification Variables as Predictors of Intragroup Behavioural Intentions

\begin{tabular}{|c|c|c|c|c|c|c|}
\hline & \multicolumn{3}{|c|}{ Volunteering } & \multicolumn{3}{|c|}{ Intentions to Leave Party } \\
\hline & $b$ & $S E$ & $\beta$ & $b$ & $S E$ & $\beta$ \\
\hline Partisan narcissism & -0.28 & 0.68 & -.03 & -0.19 & .14 & -.09 \\
\hline Partisan identification & $2.30 * *$ & 0.77 & .22 & $-0.89 * * *$ & .15 & -.38 \\
\hline Age & -0.05 & 0.04 & -.08 & $-0.04 * * *$ & .01 & -.25 \\
\hline Gender $(1=\mathrm{M}, 2=\mathrm{F})$ & -2.01 & 1.24 & -.12 & 0.01 & .25 & .00 \\
\hline$F(d f)$ & \multicolumn{3}{|c|}{$F(4,190)=2.91^{*}$} & \multicolumn{3}{|c|}{$F(4,192)=17.65$} \\
\hline$R^{2}$ & \multicolumn{3}{|c|}{.06} & \multicolumn{3}{|c|}{.27} \\
\hline Adjusted $R^{2}$ & \multicolumn{3}{|c|}{.04} & \multicolumn{3}{|c|}{.25} \\
\hline
\end{tabular}

Note. ${ }^{*} p<.05 . * * p<.01 . * * * p<.001$. 